\title{
The Feasibility of Building several New Dams to Replace the Kaliba Dam
}

\author{
Aijing Liu \\ North China Electric Power University (Baoding), Hebei 071000, China \\ 1228262272@qq.com
}

Keywords: Kariba Dam, Economic Operating Model, the reservoir regulation

\begin{abstract}
A 2015 report by the South African Institute of Risk Management warns that without urgent repairs, the whole Kariba dam will collapse. It has also led to the crisis of the Kaliba dam more and more concerned by the world. In order to study the feasibility of building a number of new dams to replace the Kaliba dam, we must conduct a series of analysis. Firstly, We assume that it is reasonable to build 16 new dams, and define a Economic Operating Model. Through this model, We analyze the correlation between dams capacity and water flow. And we also analyze the correlation between dams capacity and the water head. Through the analysis of different water flow, we study the different results in the flood and dry season and discuss their causes. Finally, a strategy for modulating the water flow through our new multiple dam system is proposed.
\end{abstract}

\section{Introduction}

According to the South African Institute of Risk Management's 2015 report, we know that if there is no urgent repairs, the whole dam will collapse. Obviously, we can not afford the enormous damage caused by its destruction. If that happened, a tsunami-like wall of water would rip through the Zambezi valley, reaching the Mozambique border within eight hours. The torrent would overwhelm Mozambique's Cahora Bassa Dam and knock out $40 \%$ of southern Africa's hydroelectric capacity. Along with the devastation of wildlife in the valley, the Zambezi River Authority (ZRA) estimates that the lives of 3.5 million people are at risk.

As one of Africa's larger dams, the construction of the Kariba Dam is controversial. Today, the Kaliba dam has been disrepaired with spillways, and associated infrastructure. We can choose to repair the existing Kariba Dam, rebuild the existing Kariba Dam, or dismantle the Kariba Dam and replace it with a series of ten to twenty smaller dams on the Zambezi River. All three scenarios require a brief assessment of some aspects (such as costs and benefits). If a new system of dams is to be built, we must ensure that it has the same or better overall water management capabilities than the Kariba Dam, while providing existing dams with the same or greater levels of protection and water management options. So a more detailed analysis is needed of the program to dismantle the Kariba dam and replace it with a series of ten to twenty smaller dams.

\section{Model Preparation}

In order to study the cost of dams, we need to study the cost of dam construction and the benefits of dams. The main benefits of the construction of the dam are shown in figure 1.

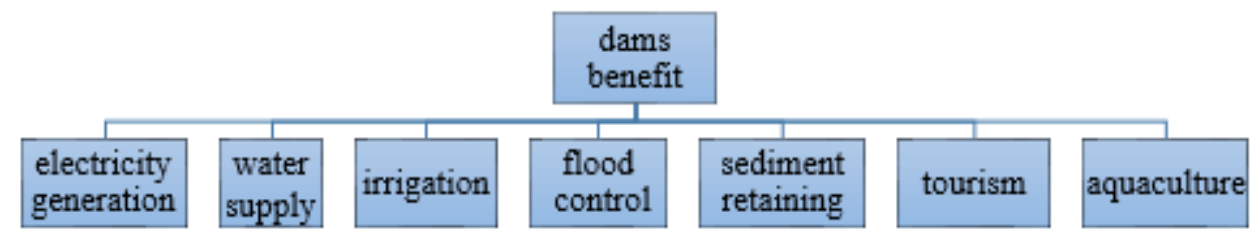

Fig. 1 The main benefits of the construction of the dam

The power generation benefit is the important benefit source of the dam. Along with the economic development, the tourism benefit will also occupy the bigger and bigger proportion.

The effects of dams on ecology environment is profound and lasting, unrecoverable, for which influence on ecosystem should be considered fully before action. 
The main components of the cost for constructing the dam are shown in figure 2.

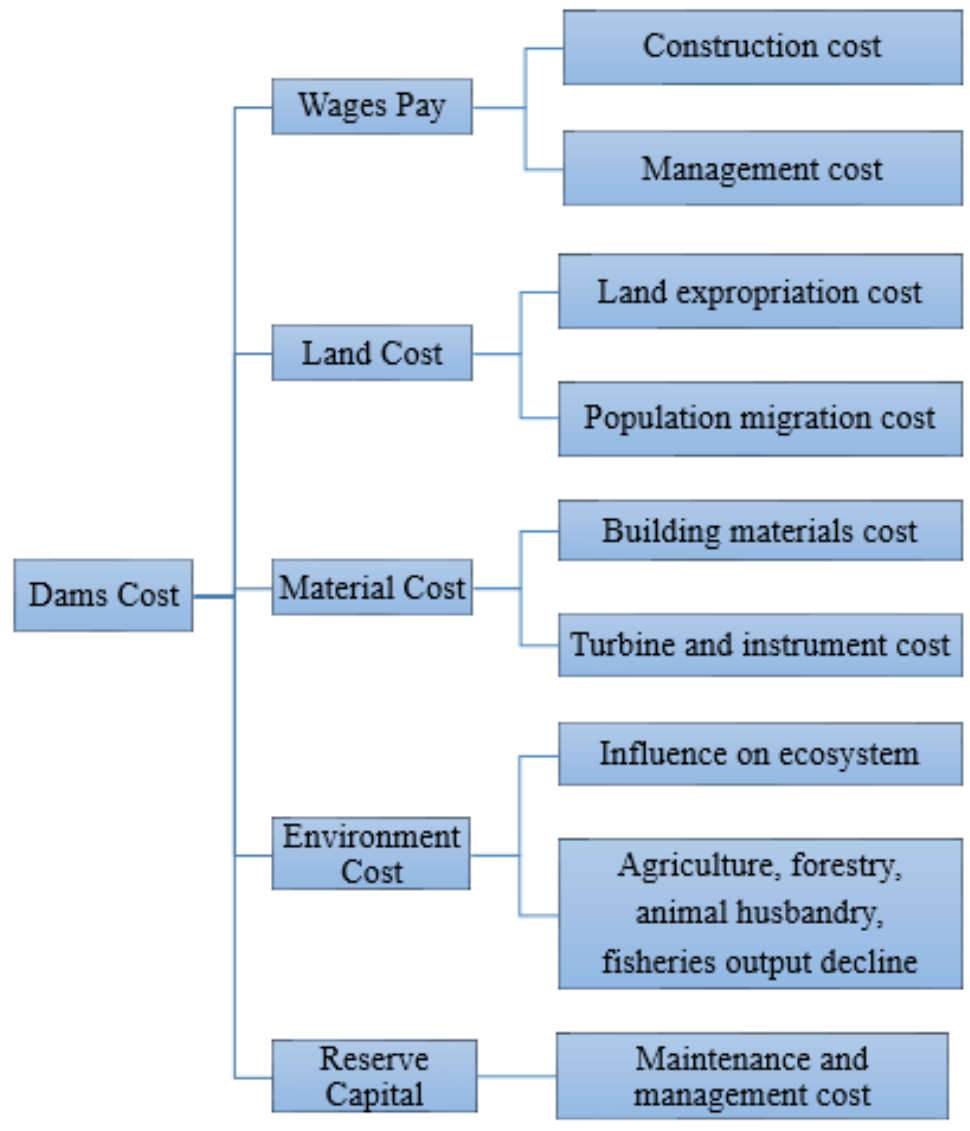

Fig. 2 The main components of the cost of constructing the dam

\section{Economic Operation Model}

In this section, we establish the models, and use the program to solve them. Through calculation and research, we will get some conclusions. Finally, these conclusions will be analyzed in detail.

\subsection{Model Establishment.}

We have established an optimal allocation model to study the optimal parameters of the dam. In order to facilitate calculation and analysis, we simplified the dam to a hydro-generator. The flow of each generator is only related to the load itself.

In order to solve the load optimal assignment problem of cascade dam, the objective function of the mathematical model can be expressed as the minimum total power flow under the premise of the total load of the power station.

The objective function is as follows:

$$
\mathrm{S}^{*}=\min \sum_{i=1}^{N} S_{i}\left(F_{i}+H_{i}\right)
$$

where $\mathrm{N}$ is total quantity of required smaller dams,

$\mathrm{i}$ is number of dams,

$F_{c}$ is total load of all dams,

$S^{*}$ is optimal total generating discharge of all dams under $F_{c}$,

$F_{i}$ is load of the ith dam,

$H_{i}$ is net head of the ith dam,

$S_{i}$ is generating discharge of the ith dam.

Constraints are as follows: 


$$
F_{i, \min } \leq F_{i} \leq F_{i, \max }
$$

where $F_{i, \min }$ is the minimum possible load of the ith dam,

$F_{i, \max }$ is the maximum possible load of the ith dam.

$F_{i, \min }$ and $F_{i, \max }$ are constrained by the capacity of the hydro-generators of the dam, and they are also functions of the working water head $H_{i}$ and the working flow $S_{i}$.

$$
S_{i, \min } \leq S_{i} \leq S_{i, \max }
$$

where $S_{i, \min }$ is the minimum possible flow of the ith dam,

$S_{i, \max }$ is the maximum possible flow of the ith dam.

$S_{i, \min }$ and $S_{i, \max }$ are functions of the working water head $H_{i}$.

$$
\sum_{i}^{N} F_{i}=F_{c}
$$

Based on this distribution optimization model, we analyze the power supply situation and the scheduling of dams.

\subsection{Results.}

Through the analysis of different water flow, we study the different results of flood and dry season, and the results are shown in Figure 3, Figure 4 and Figure 5 shows.

The goal of the model is to minimize the total energy consumption and to meet the serious cost of water resources in the Kariba basin.

\section{Normal status}

The proportion of dam load

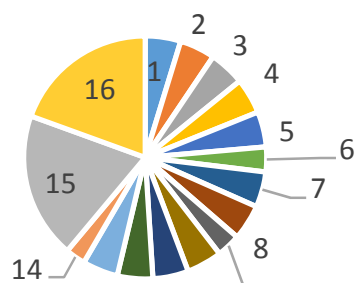

$13 \quad 121110\lfloor 9$

- $1=2 \quad-3 \quad-4 \quad-5 \quad-6 \quad \square \quad-8$

- 9 | 10 | 11 | 12 | 13 | 14 | 15 | 16

Fig. 3 Normal status
Dry season

The proportion of dam load

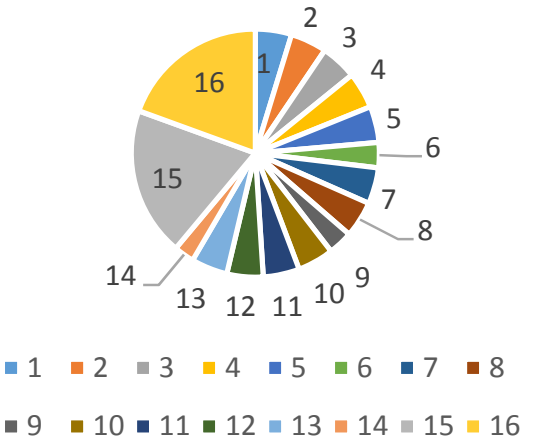

Fig. 4 Dry season

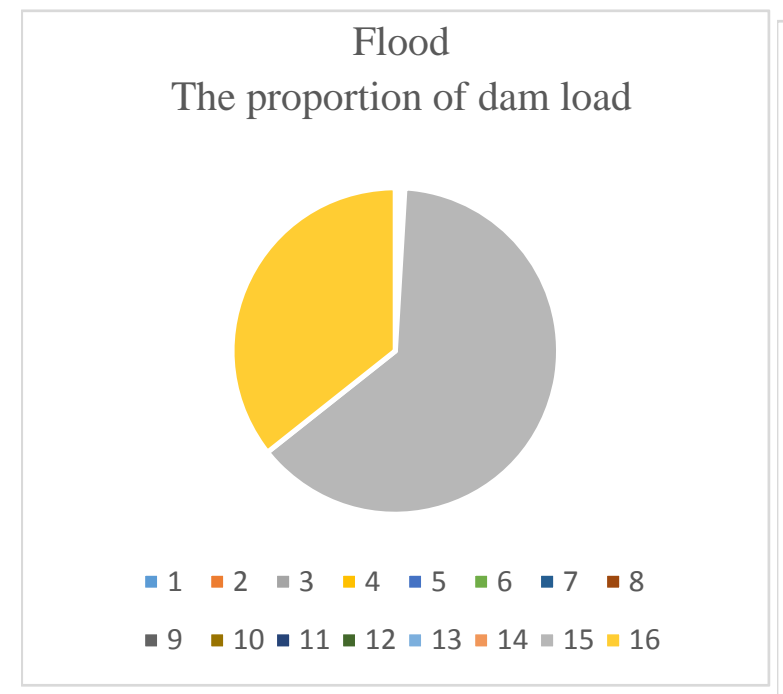

Fig. 5 Flood

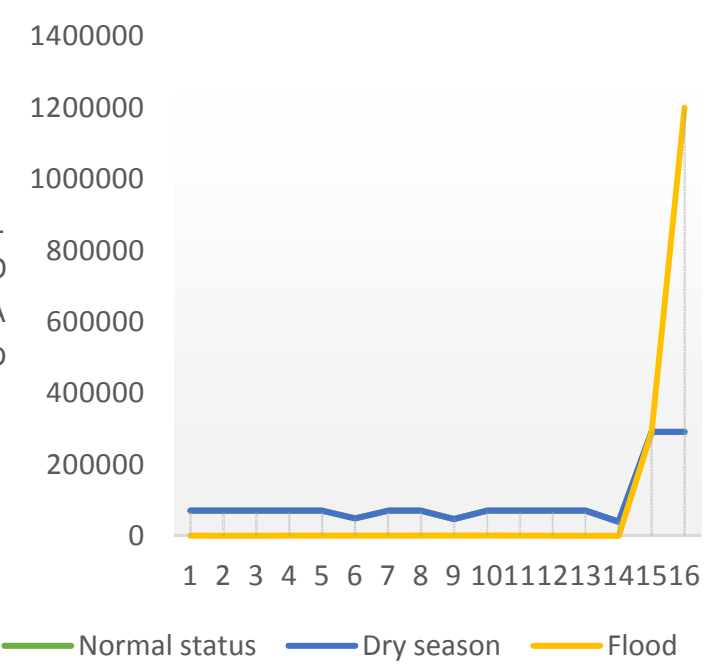

Fig. 6 The load distribution 
- Comparing figure 4 and figure 5 , it can be seen that the load distribution during the drought period is the same as that of the normal period. This indicates that the load distribution of the drought period can be distributed according to the load distribution of the normal period.

- Comparing figure 6 and figure 4, we can find that the load distribution of flood is completely different from that of the normal period. This indicates that floods have a great impact on dams load distribution. And during the flood period, the proportion of load distribution is concentrated in upstream dams, and the proportion of downstream dam load distribution is small.

- Special Dispatch of Load Distribution of Dams under Extreme Value (drought and flood). The 15th and 16th dams of upstream have a large load distribution, the load distribution of other dams is roughly the same. According to the formula of generating capacity, the water flow of the 15th and 16th dams of upstream is large, the flow of downstream is small. So in a dry situation, the 15th and 16th dam of upstream should release water to relieve load pressure, the reservoirs of downstream save water to meet the basic power generation needs.

- In flooding, the load distribution of the 15th and 16th dam are much higher than that of the downstream dams. This indicates that both the water storage capacity and the flow rate of the 15th and 16th reservoir are increasing. Which shows the degree of water release of 15th and 16th reservoir is not high, but the degree of water release of downstream reservoir is larger, the flow rate is large, the water storage capacity is insufficient.

- From the above analysis,it can be known that the upstream reservoir and downstream reservoirs have common influence on the change of water flow.

- Since natural conditions such as floods and droughts can have a significant impact on the normal operation of the dams. when we need to select the appropriate water and electricity units to get high power generation efficiency and low operating costs, the duration of the flood can not exceed the overload operation period, and the drought time can be run in the normal state.

\section{Further Discussion}

Factors affecting dam construction, such as human factors, political factors, need to be comprehensively considered. And We also have to consider the impact of other necessary facilities on the operational costs of the dam.

\section{References}

[1]. Hong Zhou, Xiao Wang, et, al. The emergency maintenance project for the Kaliba Hydropower Station in Zambia costs \$ 294 million [J]. Express Wanter Resources \& Hydropower Information, 2016, (05): 12.

[2]. Z. P. Chen, et al. Introduction to waterpower project [M]. Beijing: China WaterPower Press, 2006.

[3]. P. B. Bedient, W. C. Huber, B. E. Vieux, et al. Hydrology and floodplain analysis [M]. fourth edition. New York: Prentice Hall, 2008.

[4]. Jian Sun, Yuzhu Li, Changzhao Yu, et al. Limiting scour depth in water cushion pools produced by multiple jets [J]. Journal of Tsinghua University (Science and Technology), 2002, (02): 266269.

[5]. A. M. Geoffrion, J. S. Dyer, A. Feinberg, et al. An Interactive Approach for Multi-Criterion Optimization, with an Application to the Operation of an Academic Department [J]. Management Science, 1972:357 - 368.

[6]. Fan Hui, et al. The Construction of a Watershed Management Mechanism Based on Multicriteria Analysis [J]. Journal of Anhui Agricultural Sciences, 2012, (10): 6123-6124, 6127.

[7]. Y. Martin, C. Valeo, M. Tait, et al. Centimetre-scale digital representation of terrain and impacts on depression storage and runoff [J]. Catena, 2008, 75(2): 223 - 233.

[8]. B. Navneet, K. Rai, et al. Strategic Decision Making: Applying the Analytic Hierarchy Process [M]. London: Springer-Verlag, 2004. 